\title{
Carbon nanotube biocompatibility in plants is determined by their surface chemistry
}

\author{
Eduardo González-Grandío ${ }^{1}$, Gözde S. Demirer ${ }^{1,6}$, Christopher T. Jackson ${ }^{1}$, Darwin Yang ${ }^{1}$, Sophia Ebert²,
} Kian Molawi ${ }^{2}$, Harald Keller ${ }^{2}$ and Markita P. Landry ${ }^{1,3,4,5^{*}}$ (]

\begin{abstract}
Background: Agriculture faces significant global challenges including climate change and an increasing food demand due to a growing population. Addressing these challenges will require the adoption of transformative innovations into biotechnology practice, such as nanotechnology. Recently, nanomaterials have emerged as unmatched tools for their use as biosensors, or as biomolecule delivery vehicles. Despite their increasingly prolific use, plant-nanomaterial interactions remain poorly characterized, drawing into question the breadth of their utility and their broader environmental compatibility.
\end{abstract}

Results: Herein, we characterize the response of Arabidopsis thaliana to single walled carbon nanotube (SWNT) exposure with two different surface chemistries commonly used for biosensing and nucleic acid delivery: oligonucleotide adsorbed-pristine SWNTs, and polyethyleneimine-SWNTs loaded with plasmid DNA (PEI-SWNTs), both introduced by leaf infiltration. We observed that pristine SWNTs elicit a mild stress response almost undistinguishable from the infiltration process, indicating that these nanomaterials are well-tolerated by the plant. However, PEI-SWNTS induce a much larger transcriptional reprogramming that involves stress, immunity, and senescence responses. PEI-SWNT-induced transcriptional profile is very similar to that of mutant plants displaying a constitutive immune response or treated with stress-priming agrochemicals. We selected molecular markers from our transcriptomic analysis and identified PEI as the main cause of this adverse reaction. We show that PEI-SWNT response is concentrationdependent and, when persistent over time, leads to cell death. We probed a panel of PEI variant-functionalized SWNTs across two plant species and identified biocompatible SWNT surface functionalizations.

Conclusions: While SWNTs themselves are well tolerated by plants, SWNTs surface-functionalized with positively charged polymers become toxic and produce cell death. We use molecular markers to identify more biocompatible SWNT formulations. Our results highlight the importance of nanoparticle surface chemistry on their biocompatibility and will facilitate the use of functionalized nanomaterials for agricultural improvement.

Keywords: Plant biotechnology, Nanotechnology, DNA delivery, Carbon nanotube, RNA sequencing

*Correspondence: landry@berkeley.edu

1 Department of Chemical and Biomolecular Engineering, University

of California, Berkeley, CA, USA

Full list of author information is available at the end of the article original author(s) and the source, provide a link to the Creative Commons licence, and indicate if changes were made. The images or other third party material in this article are included in the article's Creative Commons licence, unless indicated otherwise in a credit line to the material. If material is not included in the article's Creative Commons licence and your intended use is not permitted by statutory regulation or exceeds the permitted use, you will need to obtain permission directly from the copyright holder. To view a copy of this licence, visit http://creativecommons.org/licenses/by/4.0/. The Creative Commons Public Domain Dedication waiver (http://creativeco mmons.org/publicdomain/zero/1.0/) applies to the data made available in this article, unless otherwise stated in a credit line to the data. 


\section{Graphical Abstract}

1. Nanomaterial infiltration

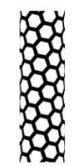

+ ssRNA

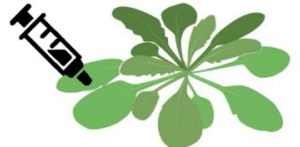

${ }_{\text {PEI }}^{\text {PEI }}$

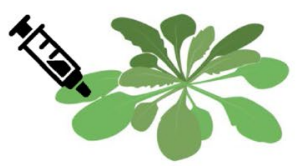

\section{Characterization of plant response}
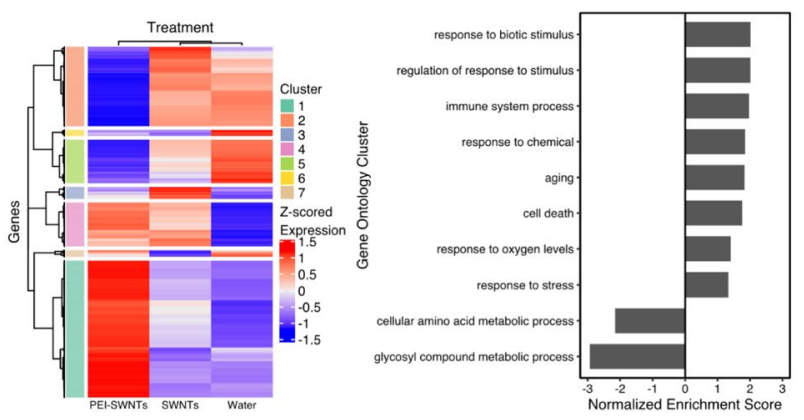

4. Generation of biocompatible nanomaterials
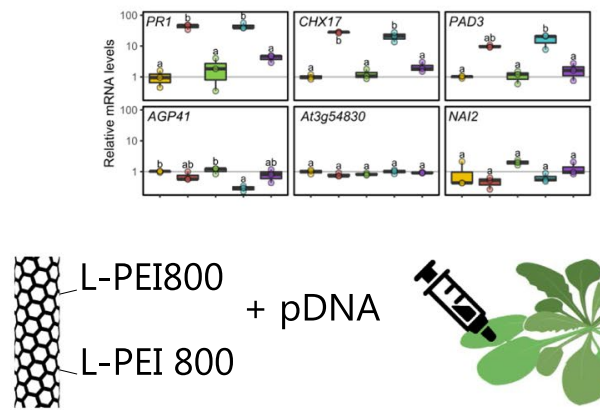

L-PEI800 + pDNA

L-PEI 800

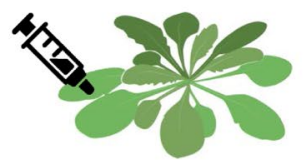

\section{Background}

Given the magnitude of environmental changes driven by climate change, and an increasing human population, plant biotechnology and bioengineering have an important role in providing food security, maintaining global biodiversity and sustainability. Technologies that sense plant stress in real-time, improve crop nutritional capacity, render plants resistant to biotic and abiotic stresses, and enable higher crop yield with fewer resources are central to these efforts [1].

Recently, nanoscience and nanoengineering technologies have been employed in numerous plant biotechnology applications [1, 2]. Nanomaterials exhibit unique and tunable size, shape, and physical, mechanical and optical properties. In plant biotechnology, a broad range of nanoparticles have been used including metal nanoparticles, quantum dots, mesoporous silica nanoparticles, clay nanosheets, DNA nanostructures and carbon nanomaterials such as graphene, carbon nanotubes and carbon dots [2]. Within the scope of plant biotechnology, these nanomaterials have been most commonly used as fertilizers, antimicrobials, sensors, imaging agents, and delivery vehicles for small molecules, genes and proteins for plant genetic engineering applications [2-4].

To accompany the growing use of nanomaterials in plant science, it is essential to understand nanomaterialplant interactions and the impact of nanomaterials on plant health and their environment. Recent studies have focused on the phenotypical phytotoxicity of metaland carbon-based nanoparticles on monocot and dicot crop species of interest [5-8], yet many of these studies show conflicting and often contradictory results. For instance, nano- $\mathrm{TiO}_{2}(5 \mathrm{~nm})$ has been shown to accelerate germination of spinach seeds [9], whereas nano- $\mathrm{TiO}_{2}$ $(20 \mathrm{~nm})$ did not alter the germination rate of wheat grains [10]. Another metal nanoparticle, nano- $\mathrm{ZnO}(20 \mathrm{~nm}$, $2000 \mathrm{mg} / \mathrm{L}$ ), has been shown to inhibit root growth in rapeseed, radish, ryegrass, lettuce, corn and cucumber [11]. Cadmium sulfide quantum dots induce oxidative stress and root lignification in soybean [12]. The most studied carbon-based nanomaterials in plant biotechnology are graphene and multi-walled carbon nanotubes 
(MWNTs). Cabbage, tomato, spinach and lettuce seeds soaked in $2000 \mathrm{mg} / \mathrm{L}$ graphene overnight had inhibited growth and reduced biomass [13]. On the other hand, MWNTs enhanced the germination and seedling root elongation when added to the wheat growth medium at $1000 \mathrm{mg} / \mathrm{L}$ [6], and stimulated the growth of roots and stems in legumes [14]. There are several studies discussing the phenotypical phytotoxicity of single-walled carbon nanotubes (SWNTs) with varying results. Studies in Arabidopsis thaliana and rice protoplasts show concentration-dependent cytotoxicity of SWNTs, while high SWNT concentrations $(250 \mathrm{mg} / \mathrm{L})$ had no observable effects on Arabidopsis leaves [15]. Some studies show that carboxylated SWNTs (COOH-SWNTs) at $50 \mathrm{mg} / \mathrm{L}$ induce growth and enhanced biomass of tomato plants [16], whereas poly-3-aminobenzenesulfonicacid functionalized SWNTs at $1750 \mathrm{mg} / \mathrm{L}$ inhibited root growth in tomato [17]. Lastly, SWNTs have been shown to reduce oxidative stress and improve cryopreservation of Agapanthus praecox embryogenic calli [18].

More recently, microarray analysis and RNA sequencing (RNA-seq) methods that leverage the advantages of next-generation sequencing have been used to determine nanomaterial impact on plant health [19-21]. Due to its complete gene sequence and annotation, Arabidopsis is the preferred plant species for transcriptomic analyses. For instance, whole-genome microarray analysis of Arabidopsis roots exposed to $100 \mathrm{mg} / \mathrm{L}$ nano- $\mathrm{ZnO}$ revealed up-regulation of genes involved in biotic and abiotic stress responses and down-regulation of genes involved in cell biosynthesis, electron transport, and energy pathways [22]. Additionally, Arabidopsis plants that were exposed to $20 \mathrm{mg} / \mathrm{L}$ nano- $\mathrm{TiO}_{2}$ had significant repression of phosphate-starvation and root-development genes [23]. Lastly, $50 \mathrm{mg} / \mathrm{L} \mathrm{MWNT} \mathrm{treated} \mathrm{tomato}$ roots showed substantial upregulation of genes coding for water-channel proteins and hormone pathways [16], in accordance with the phenotypical data demonstrating enhanced growth in the presence of MWNTs. These studies provide valuable information at the gene expression level and enable a better understanding of the nanomaterial impact on plant health.

Given the recent surge of SWNT usage in plants for sensing [24-28] and biomolecule delivery [29-32], it is critical to determine the impact of SWNTs on plant health at the molecular and gene expression level. Analogously, it is also important to pinpoint what component(s) of SWNT nanomaterials are responsible for generating differential gene expression patterns, to reconcile conflicting reports. In this study, we performed RNA-seq analysis of Arabidopsis leaves $48 \mathrm{~h}$ after exposure to $50 \mathrm{mg} / \mathrm{L}$ SWNTs with two different surface chemistries representing the most commonly used SWNT nanomaterials for plant delivery and sensing applications: oligonucleotide-adsorbed pristine SWNTs, and polyethyleneimine (PEI) conjugated functionalized SWNTs (PEISWNTs) loaded with plasmid DNA. Our results revealed that SWNTs produced a mild stress response in plants, nearly indistinguishable from a water-infiltration control, that was well tolerated and did not result in permanent damage. However, PEI-functionalized SWNTs at high concentrations produced an adverse response that was irreversible and resulted in cell death, indicating that PEI is the main cause of biotoxicity. We identified gene markers to probe plant responses to different SWNT surface chemistries and discovered new biocompatible SWNT surface chemistry formulations that will facilitate their use in plants.

\section{Results}

\section{Functionalized PEI-SWNTs generate a very distinct} transcriptional response compared to un-functionalized SWNTs

Given the widespread use of PEI-functionalized nanomaterials for delivery of DNA and RNA in plants [30, 32-34], we sought to investigate the reaction of plant tissues to treatment with PEI-SWNTs versus pristine SWNTs. To this end, we infiltrated Arabidopsis leaves with pristine single walled carbon nanotubes used in RNA silencing applications (SWNTs) [30] and polyethyleneimine-functionalized SWNTs used for plasmid DNA delivery (PEI-SWNTs, Additional file 1: Table S1) [32]. We used Arabidopsis as it is a well-characterized model plant for which genomic and detailed gene function information is readily available. Aforementioned pristine SWNT and PEI-SWNT nanoparticles were loaded with single stranded RNA targeting Green Fluorescent Protein (GFP) with no target sequence in the Arabidopsis genome, and a GFP-expressing plasmid [35], respectively. For experiments herein, we used 25-50 fold higher concentrations of SWNTs and PEI-SWNTs compared to standard concentrations used in biomolecule delivery assays to ensure we would observe a robust transcriptional change. Water-infiltrated plant leaves served as a negative control to distinguish between the SWNT-specific response and the response to the infiltration process itself (Fig. 1A). We performed RNA-seq with RNA extracted from leaves $48 \mathrm{~h}$ post infiltration to identify changes in the leaf transcriptomic profile in response to the three treatments, compared to non-infiltrated leaves. We validated the RNA-seq data by measuring the expression changes in 12 selected genes using reverse transcription quantitative polymerase chain reaction (RT-qPCR) (Additional file 1: Fig. S1). Changes in gene expression measured by RNA-seq and RT-qPCR correlated well, confirming the reliability of the RNA-seq data. 

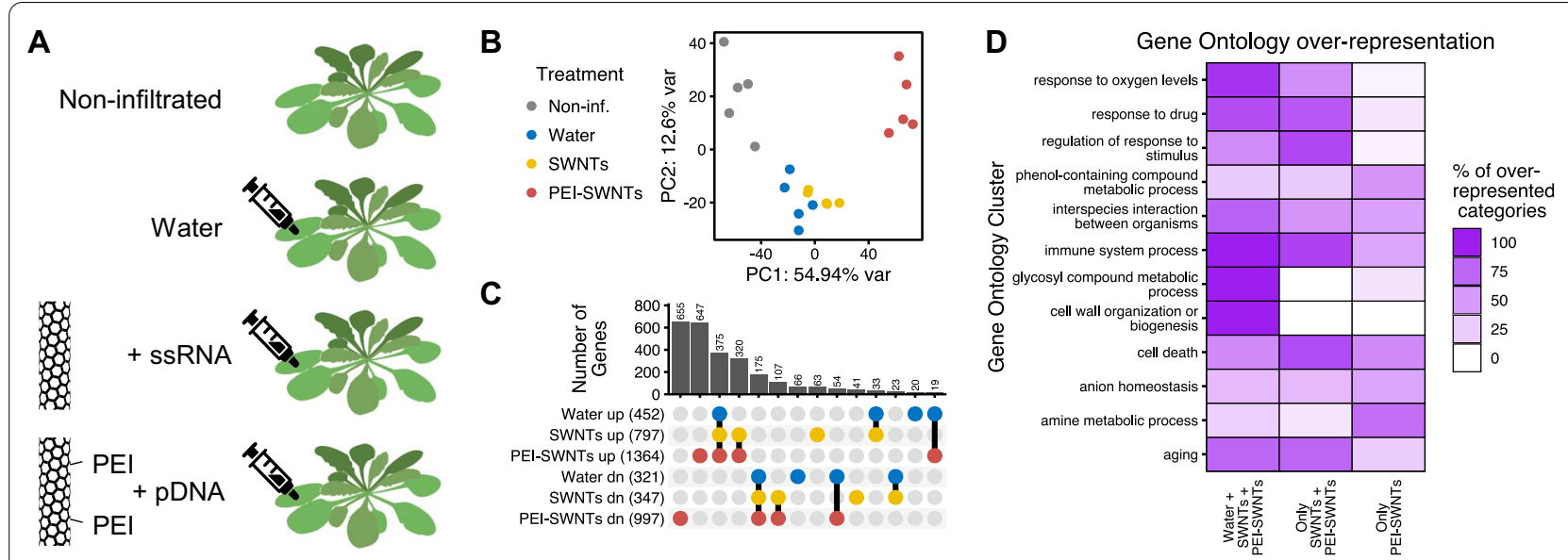

Fig. 1 PEI-SWNTs elicit a very distinct transcriptional response compared to that of water or SWNTs. A Experimental setup: Arabidopsis leaves were infiltrated with ssRNA-adsorbed pristine SWNTs or plasmid-loaded PEI-SWNTs. Non infiltrated and water-infiltrated leaves were used as controls. Samples were collected $48 \mathrm{~h}$ post infiltration. B Principal Component Analysis of the transcriptomic profile in response to the different treatments. Each dot represents one biological replicate. C Upset plot showing the number of up- or down-regulated genes common or specific to each treatment. Genes with a statistically significant (FDR $<0.05)$ two-fold change in expression relative to non-infiltrated samples were selected. D Functional characterization of genes differentially expressed in the three treatments (375 up, 175 down), specifically in SWNTs and PEI-SWNT samples (320 up, 107 down), and uniquely in PEI-SWNT samples (647 up, 655 down). For a full list of GO terms, see Additional file 2: Table S2

RNA-seq data was first analyzed with Principal Component Analysis (PCA) of the whole transcriptomic profile of each sample to assess which treatments induced the largest changes in the plant leaf transcriptome. Surprisingly, PCA analysis revealed that plant response to infiltration with SWNTs is very similar to the response to the water infiltration control, suggesting that SWNTs themselves do not elicit a general transcriptional reprogramming beyond that generated by the infiltration process itself. These results are surprising because they suggest the high concentrations of SWNTs used in our experiments may be biocompatible for use in plants. Conversely, PCA clustering of PEI-SWNTs samples showed that the plant response to PEI-SWNT treatment is distinct relative to SWNT treatment or treatment with water alone (Fig. 1B), suggesting that nanoparticle surface chemistry could dictate nanoparticle biocompatibility.

Next, we selected genes that showed a statistically significant (false discovery rate $<0.05$ ) two-fold expression change with respect to the non-infiltrated samples for further analysis. We identified 452, 797, and 1364 upregulated genes in water, SWNT and PEI-SWNT treated leaf samples, respectively. Conversely, we identified 321, 347, and 997 down-regulated genes in water, SWNT and PEI-SWNT treated leaf samples (Fig. 1C; Additional file 2: Table S2). These results quantitatively confirmed the hypothesis that PEI-SWNTs cause much greater transcriptional reprogramming than the other two treatments. We compared the common genes that respond to the three treatments and observed that $94 \%(427 / 452)$ of the up- and 79\% (252/321) of the down-regulated genes in response to water infiltration also changed in SWNT and PEI-SWNT samples, representing genes that change in response to the infiltration process and are independent of a nanomaterial-specific response. Next, to identify biological processes that were present at higher than random fraction when compared to the Arabidopsis genome, we performed a Gene Ontology (GO) over-representation analysis. Water/SWNT/PEI-SWNT common genes showed a very significant over-representation of processes related to hypoxia, as expected from injecting a liquid into the leaf tissue that contains large air spaces. Additionally, many GO categories related to cell wall organization, immune response, senescence (aging/programmed cell death), glycosinolate biosynthesis (defense metabolites) and biotic and abiotic stresses were overrepresented in this gene set (Fig. 1D; Additional file 3: Table S3A). These results suggest that the infiltration process produces a hypoxia response that triggers other stress-related genes. The fact that we did not observe any phenotypical change in response to water infiltration suggests that this transcriptomic response is insufficient to trigger observable physiological changes in Arabidopsis leaves.

We next focused our study on genes that change specifically following treatments with carbon nanotubes, that is, genes that change in leaves infiltrated with SWNT and PEI-SWNT, but do not change following water infiltrations. A majority of genes that change in response to SWNTs also change in response to PEI-SWNTs $(76 \%$ or 
$320 / 422$ of up- and $62 \%$ or $107 / 172$ of down-regulated genes in SWNTs samples), indicating that these genes are involved in the response to the presence of carbon nanotubes independent of their surface functionalization. GO over-representation analysis showed that genes related to hypoxia, immune response, biotic and abiotic stress responses are also over-represented in this gene set (Fig. 1D; Additional file 3: Table S3B). These results suggest that the presence of carbon nanotubes magnifies the responses to infiltration, because in this analysis we excluded genes that change in all three treatments (e.g., 38 genes in the cellular response to hypoxia GO category change in all three treatments, while 39 additional genes in the same GO category change only in SWNTs and PEI-SWNTs samples (Additional file 3: Table S3A, B). Lastly, certain GO categories including those related to cell death and aging are more over-represented in this gene set when compared to the Water/SWNT/PEISWNT genes. These results suggest that the presence of carbon nanotubes exacerbates the plant response triggered by the infiltration process and could indicate that a more advanced response is occurring in these samples at this $48 \mathrm{~h}$ time point. On the other hand, cell wall reorganization and glycosinolate biosynthesis-related processes are not over-represented categories in the SWNT/ PEI-SWNT gene set (Fig. 1D), indicating that nanotube responses are specific and not a general amplification of the stress caused by infiltration.

PEI-SWNTs induce a much greater transcriptomic reprogramming than water or SWNT treatments, with 647 and 655 up- and down-regulated genes exclusively in PEI-SWNT treated leaves (Fig. 1C). In PEI-SWNT treated leaves, we further observed an over-representation of immune system and cell death processes. In plants, a prolonged immune response often leads to programmed cell death [36], indicating that the plant response to PEI-SWNTs could be more detrimental to treated tissues than less stressful water or SWNT treatments. At the same time, we observe that responses related to aromatic amino acid and secondary metabolite biosynthesis are highly over-represented in PEISWNT samples relative to SWNT or water-treated leaves (Fig. 1D). Specifically, genes involved in Tryptophan and salicylic acid biosynthesis are specifically over-represented in the PEI-SWNT response. These results indicate that PEI-SWNT specific responses focus on metabolism reconfiguration affecting both primary (i.e., aromatic amino acids) and secondary metabolites involved in defense responses derived from those aromatic amino acids (i.e., salicylic acid) [37]. Taken together, our RNAseq results suggest that water infiltration alone triggers a mild stress response, one which is highly and at times irreversibly exacerbated by the presence of PEI-SWNTs in a manner not observed following treatment with SWNTs. These results highlight the importance of nanoparticle surface chemistry on nanoparticle biocompatibility in plants.

\section{PEI-SWNTs strongly up-regulate stress responses and programmed cell death genes, and down-regulate metabolism-related genes}

To better characterize the large transcriptional reprogramming of plant leaves treated with PEI-SWNTs, we focused our study on the PEI-SWNT-responding genes that had the highest expression-fold change when compared to water or SWNT treatments, based on the notion that these genes could be the main contributors to the PEI-SWNT specific response. Clustering analyses of gene expression levels in the three treatments revealed a group of 1063 genes that showed very high expression levels in PEI-SWNT treated samples compared to their levels in the other treatments (Fig. 2A, Cluster 1). Conversely, 631 genes showed greatly decreased expression levels in PEI-SWNTs when compared to the two other treatments (Fig. 2A, Cluster 2). These genes show a very distinct expression profile in PEI-SWNTs compared to the two other treatments, although they can still be upor down-regulated to a much lesser degree in response to SWNTs or water. We conducted a Gene Set Enrichment Analysis (GSEA) [38] with these PEI-SWNT specific genes. This powerful analytical method incorporates the degree of gene expression changes in its statistical analysis to produce a quantitative normalized enriched score (NES). This NES represents how a specific gene set (e.g. hypoxia response genes) is enriched in the most up-regulated (positive NES) or most down-regulated (negative NES) genes in a transcriptomic profile used as query (in this case, PEI-SWNT specific genes). GSEA using biological process GOs showed that up-regulated PEI-SWNTspecific genes are enriched in genes related to biotic and abiotic stress responses, defense responses, senescence, and programmed cell death. Down-regulated genes are involved in amino acid and glycosinolate biosynthesis (Fig. 2B; Additional file 4: Table S4A). These results further confirm that PEI-SWNTs induce a programmed cell death response in leaves, in a process that involves metabolism suppression.

We also compared the transcriptomic profile of the PEI-SWNT specific genes with other publicly available genome-wide transcriptomic experiments (AraPath and PlantGSEA $[39,40]$ ) to find similar profiles that would give us more insight on which processes are involved in the plant response to PEI-SWNTs. This analysis revealed that the expression pattern observed in response to PEI-SWNTs is similar to stress, senescence, and defense responses generated by very 

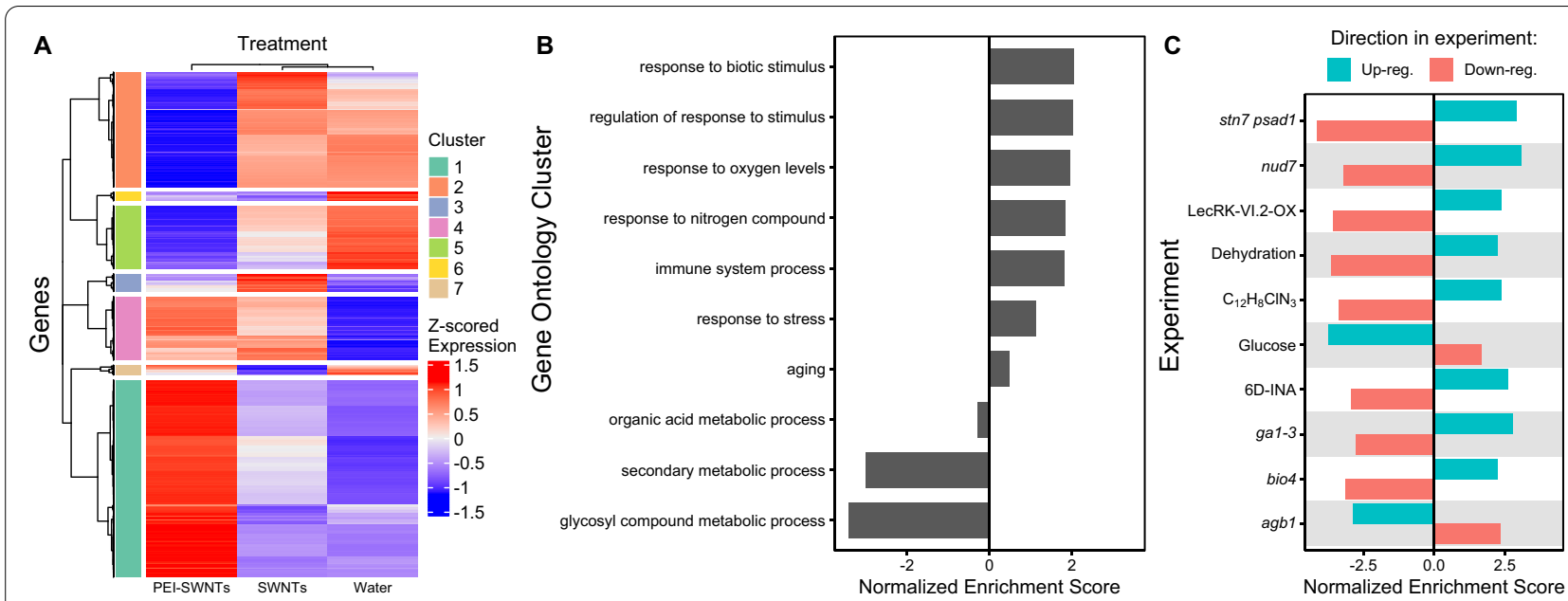

Fig. 2 PEI-SWNT responding genes are involved in stress responses, immune system, and programmed cell death. A Gene expression heatmap of genes with statistically significant two-fold expression change in at least one of the three treatments, compared to non-infiltrated samples. Clusters 1 and 2 show PEI-SWNT specific up- and down-regulated genes. B, C Gene Set Enrichment Analysis of Cluster 1 and 2 genes using Biological Process Gene Ontology categories (B), and Arapath and PlantGSEA databases (C). Up- or down-regulation genes in the original experiment were used as independent gene sets to calculate their normalized enriched score. Details corresponding to each experiment can be found in Additional file 4: Table S4C

different stimuli (Fig. 2C; Additional file 4: Table S4B). Among the most similar transcriptomic profiles, we can find several profiles of Arabidopsis mutant plants with altered defense responses, like $\operatorname{stn} 7$ psad1 double mutants defective in photosynthesis acclimation [41], nud7 mutants with higher levels of reactive oxygen species [42], plants over-expressing a lectin receptor kinase that constitutively activates immune responses (LecRK-VI.2) [43], bio4 biotin defective mutants that show spontaneous cell death [44] or agb1 plant defense signaling heterotrimeric G-protein mutants [45]. Also, PEI-SWNT-induced transcriptomic changes were similar to those of plants treated with chemicals that trigger defense responses like the salicylic acid analog 2,6-dichloroisonicotinic acid [46] or the slow xenobiotic response inducer 4-chloro-6-methyl-2-phenylpyrimidine [47]. Likewise, the PEI-SWNT specific gene expression pattern was similar to that of plants under dehydration [48] and opposite to those of plants treated with glucose [49], suggesting that PEI-SWNT specific genes are involved in responses to metabolic stress (Additional file 4: Table S4C). Furthermore, GSEA of genes specifically differentially expressed in response to both SWNTs and PEI-SWNTs (Fig. 2A, Clusters 4 and 6 , up- and down-regulated, respectively) showed highly similar results to the GO over-representation analysis, with response to stress, biotic stimulus and hypoxia being enriched in the up-regulated genes (Additional file 2: Table 2B). In summary, GSEA using GO and publicly available experiments indicate that the leaf response to treatment with PEI-SWNTs involves stress, immunity, and senescence-related genes.

Finally, we also compared the PEI-SWNT response to profiles of Agro-infiltrated Arabidopsis plants, the most widely used technique for transient gene expression in plants [50]. We observed a weak but statistically significant enrichment of genes that are up-regulated at $24 \mathrm{~h}$ and $48 \mathrm{~h}$ in response to virulent and avirulent Agrobacterium strains (Additional file 4: Table S4D). Up-regulated PEI-SWNT-responding genes that are also up-regulated in response to Agrobacterium are mainly involved in detoxification and senescence (e.g., PCR2, involved in Zinc detoxification; and FRK1, Flagellin/Senescence induced receptor-like kinase1). Conversely, we did not detect an enrichment of agrobacterium down-regulated genes in PEI-SWNT down-regulated genes. Our comparison suggests that the plant response to PEI-SWNT treatment is only partially similar to Agrobacterium response.

\section{PEI is the main cause of toxicity in functionalized PEI-SWNTS}

Our results thus far highlight the importance of nanoparticle surface chemistry on inducing differential gene expression patterns in nanoparticle-treated leaves. Specifically, as we observed that PEI-SWNT treatments elicited a much larger transcriptional reprogramming than SWNT treatments, we hypothesized that this difference could be caused by the surface-functionalization of SWNTs with PEI. To better characterize the plant response to PEI-SWNTs, we conducted a more 
detailed experiment in which we infiltrated increasing concentrations of PEI-SWNTs into Arabidopsis leaves. We selected three PEI-SWNT specific genes with large expression changes from the up-regulated Cluster 1 (PR1, CHX17 and PAD3) and the down-regulated Cluster 2 (AGP41, At3g54830 and NAI2), and used these genes as molecular markers to probe the PEI-SWNT concentration-dependent response $48 \mathrm{~h}$ post-infiltration (Fig. 3A). Leaves of plants treated with high concentrations of PEI-SWNTs (25 and $50 \mathrm{mg} / \mathrm{L}$ ) showed some visible damage, especially around the infiltration area, indicating that higher PEI-SWNT concentrations are more toxic to the plant (Fig. 3B). We next measured mRNA expression levels of the six marker genes by RTqPCR in these samples and observed a clear correlation of their expression proportional to PEI-SWNT concentration. Expression of Cluster 1 genes increased with
PEI-SWNTs concentration, while expression of Cluster 2 genes decreased (Fig. 3C). PEI-SWNTs were loaded with plasmid DNA, but the exogenous DNA does not seem to be the cause of toxicity as leaves infiltrated with no-DNA PEI-SWNTs showed very similar gene expression to plants infiltrated with DNA loaded PEISWNTs (Fig. 3C). Importantly, COOH-SWNTs, the starting material used for PEI-SWNT functionalization, did not cause any significant change in gene expression even when infiltrated at very high $(50 \mathrm{mg} / \mathrm{L})$ concentrations (Fig. 3C). We performed an additional experiment in which we infiltrated Arabidopsis leaves with free PEI and we observed even clearer signs of toxicity compared to PEI-SWNT infiltration (Additional file 1: Fig. S2). These results clearly indicate that PEI is the main causative factor of gene expression changes in plants exposed to PEI-SWNTs.

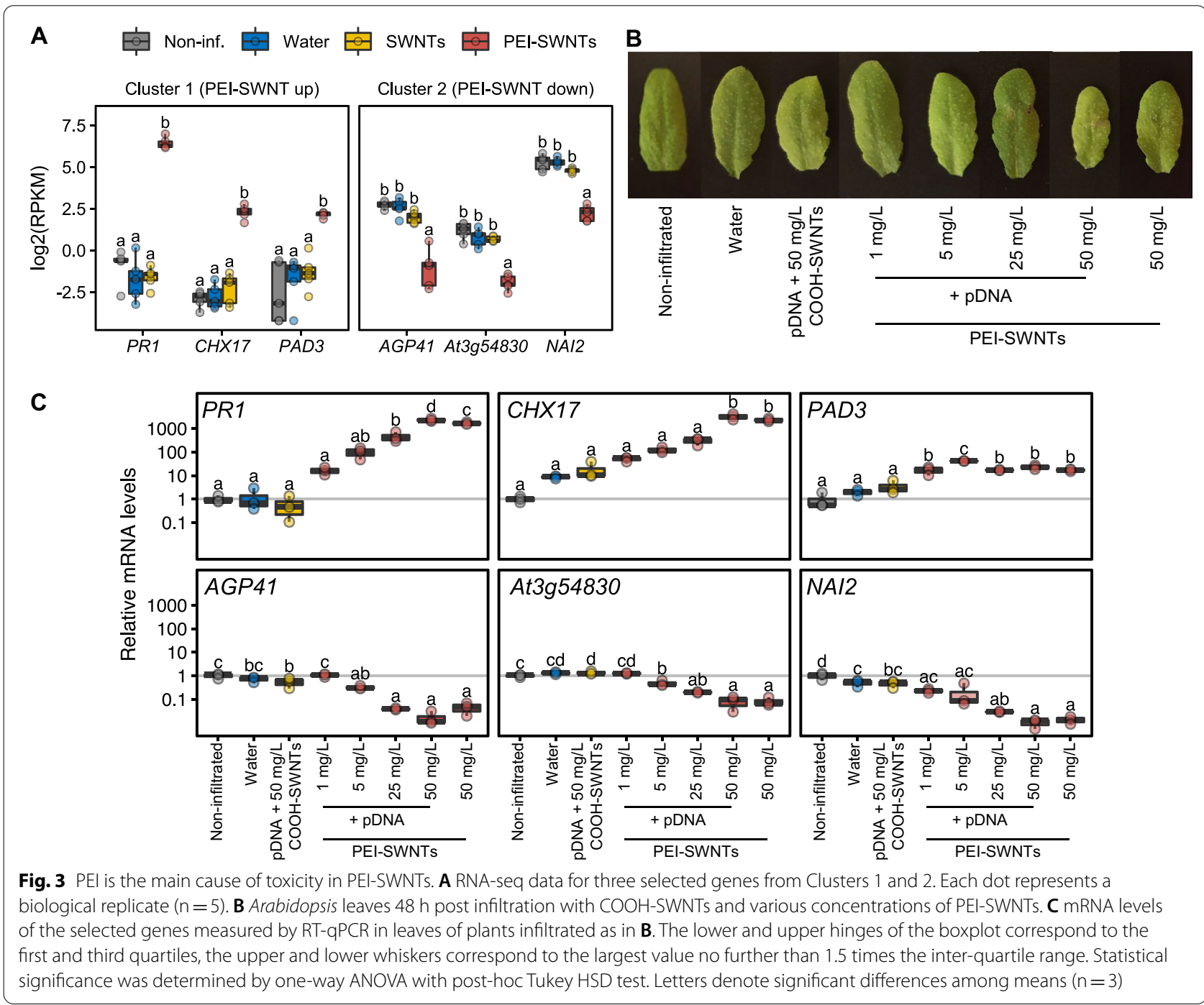


Persistent PEI-SWNT specific response leads to leaf damage In our initial experiments, we studied the response to PEI-SWNTs at relatively short times after infiltration $(48 \mathrm{~h})$. To gain better insight into the long-term effects of PEI-SWNTs infiltration, we performed a time course experiment where we infiltrated low $(1 \mathrm{mg} / \mathrm{L}$, equivalent to the dose used in standard delivery experiments) and high $(50 \mathrm{mg} / \mathrm{L})$ concentrations of PEI-SWNTs, and collected samples 2-, 4-, 6- and 8-days post infiltration (dpi). Again, we detected some leaf damage in $50 \mathrm{mg} / \mathrm{L}$ infiltrated samples by the 2-dpi time point. This damage increased as time advanced, with slight leaf chlorosis and evident cell death around the infiltration area the later time points, indicative of a strong stress response (Fig. 4A). These symptoms were not apparent in $1 \mathrm{mg} / \mathrm{L}$ PEI-SWNT infiltrated leaves, suggesting that low PEI concentrations do not elicit this toxic response over time. We measured expression levels of the 6 marker genes by RT-qPCR at each time-point. The measured expression patterns were consistent with our previous results at 2-dpi, whereby $50 \mathrm{mg} / \mathrm{L}$ PEI-SWNTs induced larger expression changes than $1 \mathrm{mg} / \mathrm{L}$ PEI-SWNTs. Expression of up-regulated genes (PR1,CHX17 and PAD3) decreased over time for both treatments, with $50 \mathrm{mg} / \mathrm{L}$ samples always showing higher levels than $1 \mathrm{mg} / \mathrm{L}$. At 6 -dpi, expression levels of these genes in $1 \mathrm{mg} / \mathrm{L}$ samples returned to values close to basal levels (non-infiltrated samples) indicating that the response to low concentration of PEI-SWNTs had subsided. Conversely, even at 8-dpi, expression in $50 \mathrm{mg} / \mathrm{L}$ samples was still higher than non-infiltrated samples. RT-qPCR analysis of downregulated genes (AGP41, At3g54830 and NAI2) showed similar trends, albeit with a more variable expression pattern at later timepoints. AGP41 showed a stable pattern, with greater downregulation in $50 \mathrm{mg} / \mathrm{L}$ samples than in $1 \mathrm{mg} / \mathrm{L}$ samples at every time point, recovering to basal levels in $1 \mathrm{mg} / \mathrm{L}$ samples at 8-dpi. Meanwhile, At3g54830 and NAI2 were down-regulated at 2-dpi, up-regulated at 4-dpi in $50 \mathrm{mg} / \mathrm{L}$ samples, and down-regulated again at later time points. Their expression in $1 \mathrm{mg} / \mathrm{L}$ samples decreased at 4-dpi and recovered to basal levels at 6- and 8-dpi (Fig. 4B). These results suggest that a prolonged activation of PEI-SWNT specific genes generates a more severe and irreversible programmed cell death response.

\section{Identification of biocompatible functionalized SWNTs}

Our results demonstrate that toxicity generated by PEI in PEI-SWNTs can become a limiting factor when high concentrations of PEI-SWNTs are required to ensure efficient biomolecule delivery. To find more biocompatible SWNT surface chemistries we infiltrated Arabidopsis leaves with several PEI polymer variants covalently bound to SWNTs with similar zeta potential and DNA binding capabilities to PEI -SWNTs [51]. We infiltrated $50 \mathrm{mg} / \mathrm{L}$ of SWNTs functionalized with low molecular weight linear PEI (800 Da; L-PEI 800), hydrophobically modified branched PEI (25-30 kDa; H-PEI) and high molecular weight branched PEI (750 kDa; PEI 750 k). We
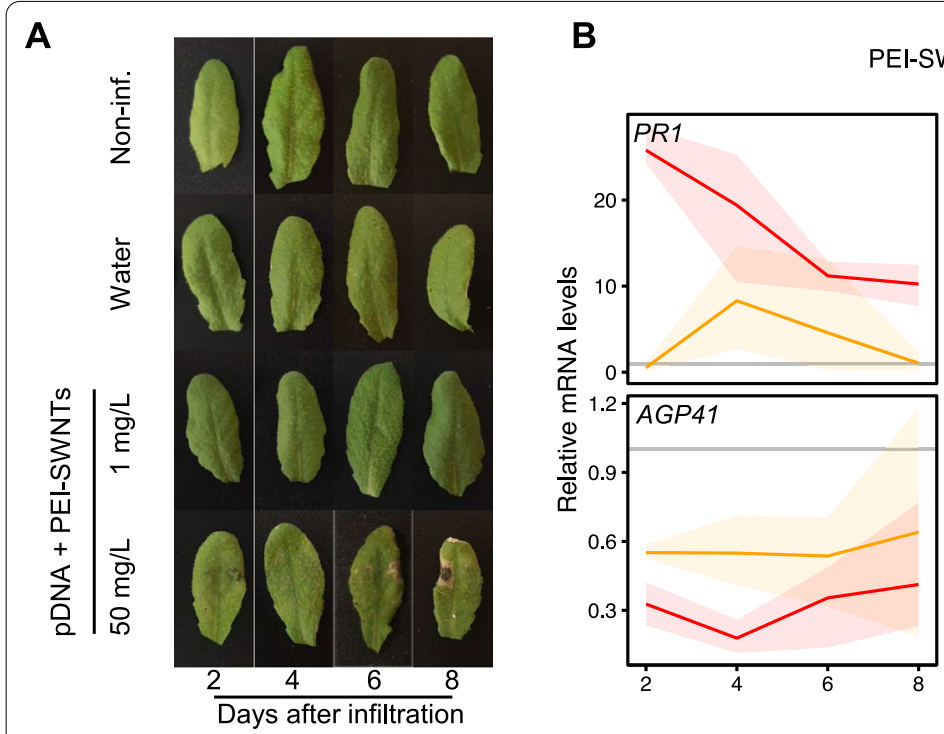

PEI-SWNT concentration - $1 \mathrm{mg} / \mathrm{L}-50 \mathrm{mg} / \mathrm{L}$

Fig. 4 Persistent PEI-SWNT specific gene response leads to severe leaf damage. A Arabidopsis leaves infiltrated with different PEI-SWNTs concentrations. Images taken two, four, six and eight dpi. B mRNA levels of selected marker genes at different time points after infiltration. mRNA levels are normalized to non-infiltrated samples at the corresponding time point (represented by a grey line). Each colored line represents the average mRNA levels at each time point and the faded band represents a 95\% confidence interval $(n=3)$ 
included unfunctionalized COOH-SWNTs and branched PEI-SWNTs (25 kDa; PEI) as negative and positive toxicity controls, respectively (Fig. 5A). We measured mRNA levels of the 6 toxicity marker genes 2-dpi and found that L-PEI 800 showed an expression pattern very similar to $\mathrm{COOH}-\mathrm{SWNTs}$ (Fig. 5B), indicating that SWNTs functionalized with this polymer are more biocompatible than PEI-SWNTs. H-PEI showed a similar pattern to PEI, while PEI $750 \mathrm{k}$ showed a lower degree of toxicity.

Lastly, to probe whether our biocompatibility results from Arabidopsis would be applicable to other plant species, we tested the response of Nicotiana benthamiana to our polymer-SWNTs. Nicotiana is another model plant species that was used to develop the PEISWNT delivery technique [32], and is an extremophile [52] that tolerates abiotic stresses better than Arabidopsis. We identified the Nicotiana orthologs of Arabidopsis PR1 and AGP41 (PR1A and NbAGP41) and used them as molecular markers of toxicity. With the same panel of polymer-SWNTs, we measured their mRNA levels 2-dpi. We only observed slight chlorosis in PEI-SWNT infiltrated samples (Fig. 5C). As in Arabidopsis, L-PEI 800-SWNTs showed an expression pattern very similar to that of $\mathrm{COOH}-\mathrm{SWNTs}$, indicating that this polymer also does not elicit a further stress response in Nicotiana (Fig. 5D). Surprisingly, PR1A levels after H-PEI- and PEI $750 \mathrm{k}-S W N T s$ infiltration were the opposite of what we observed in Arabidopsis: H-PEI-SWNTs seemed to be well tolerated in Nicotiana, while PEI 750 k-SWNTs induced a similar response to PEI-SWNTs. These results suggest that there might exist species-specific responses to different SWNT formulations, highlighting the importance of adapting SWNTs functionalization to the species being targeted to maximize biocompatibility. We propose that the data obtained in our RNA-seq experiment can be used as a starting point for the identification of molecular

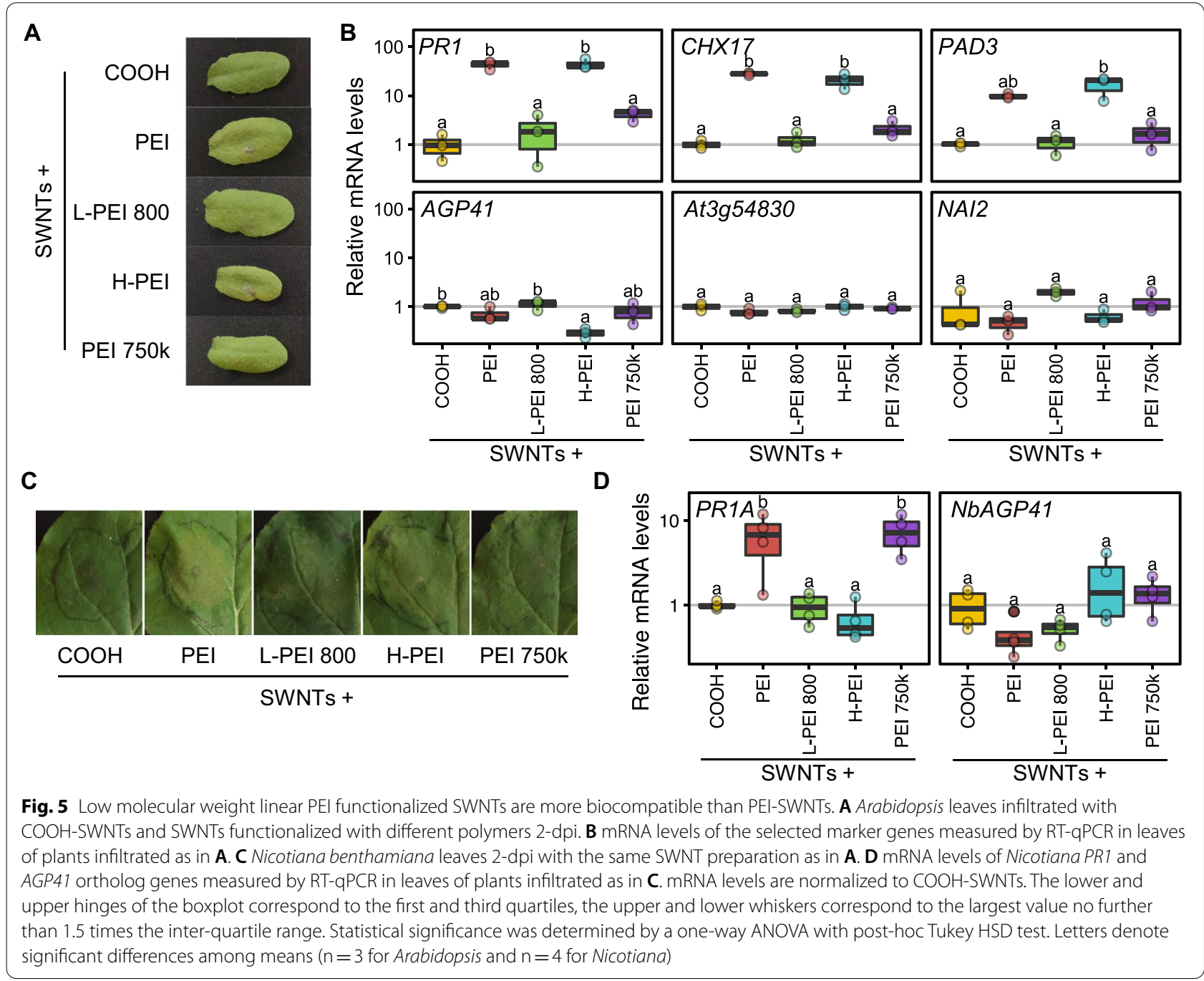


markers that guide generation of nanoparticle-based biotechnologies with enhanced biocompatibility in plants.

\section{Discussion}

Biomolecule delivery and metabolite sensing by carbonbased nanoparticles, such as SWNTs, have emerged as promising technologies to monitor plant health $[26,28]$, enable precise gene downregulation (siRNA delivery $[30,33])$ and transient gene expression (plasmid DNA delivery by PEI-functionalized nanomaterials [32, 34]). One main advantage of nanoparticle-based biomolecule delivery is that the mechanism by which these nanomaterials penetrate the cells is species-independent [53], and thus, they can be used in plant species recalcitrant to current delivery methods. Present knowledge on plant-nanomaterial interactions focuses mainly on nanomaterials applied to soil or plant growth medium [1, 54]. Understanding the mechanistic basis of how plants react to nanomaterials such as PEI-SWNTs once they are inside the cell, and identifying the key components of nanoparticles that generate bioincompatible outcomes, is crucial to inform rational improvement of these new technologies.

In this work we implement high-throughput sequencing to provide evidence that the infiltration of SWNTs produces a stress response in plants related to hypoxia, immune system activation, and senescence. This reaction is very similar to the response to the infiltration process itself and is well-tolerated by the endogenous detoxifying mechanisms of the plant. Previous studies in which much higher SWNT concentrations were infiltrated into Arabidopsis leaves $(250 \mathrm{mg} / \mathrm{L}$, five-fold the highest concentration used in our study) did not detect any macroscopic change either, suggesting that SWNTs can be well tolerated by plants [15]. Even at these high concentrations, transient activation of reactive oxygen scavenging mechanisms seem to be sufficient to eliminate any temporal toxic effects caused by nanomaterials [15].

However, these stress responses are greatly exacerbated by the presence of PEI in functionalized SWNTs, the main cause of toxicity when high concentrations of PEISWNTs are infiltrated. To our knowledge, no PEI toxicity studies have been reported in plants. We observed that PEI-SWNT specific responses are concentrationdependent and when sustained over time, lead to visible tissue damage in tissues exposed to a high concentration of PEI-SWNTs. PEI exerts a wider transcriptional reprogramming that leads to metabolism suppression and programmed cell death in the infiltrated areas. These responses are only partially similar to those elicited by other commonly used nucleic acid delivery techniques, such as agroinfiltration [50], indicating that these PEISWNT-induced responses are specific to nanomaterial functionalization. Most importantly, these results highlight that nanoparticle surface chemistry, moreso than the nanoparticle itself, can drive the biocompatibility or lack thereof of SWNT-based plant biotechnologies, a finding that may be extendible to other nanoparticle types.

Generally, nanoparticle-mediated biomolecule delivery is less efficient than conventional biotic delivery methods such as Agro-infiltration. Our results highlight that this lower efficiency cannot be overcome by simply increasing the amount of delivered PEI functionalized nanoparticles, as they show toxic effects when plants are treated with high concentrations. Thus, to identify more biocompatible SWNT preparations, we measured the response of marker genes identified in our transcriptomic analysis to SWNTs functionalized with a panel of cationic polymers. We observed that in Arabidopsis, low molecular weight linear PEI resulted in a lower toxicity response, suggesting this functionalization as a viable alternative to the currently used PEI. It is interesting that the low stress response to L-PEI 800 observed in Arabidopsis is conserved in Nicotiana, suggesting that this polymer's uniquely small size and lower amine density plays a key role in not triggering stress response pathways across plant species. Similarly, the response to PEI-750 k is conserved across both species tested. Counterintuitively, we attribute the relatively low toxicity of this polymer to its large size, which may limit its ability to internalize in cells. Further characterization of PEI-750 k-functionalized SWNTs cellular location is needed to ascertain the mechanism underlying this unexpected response. Separately, the species-specific response to H-PEI supports the importance of hydrophobicity in nanomaterial interactions with aqueous cellular components. We hypothesize that the lack of response in Nicotiana could be attributed to alternate mechanisms for managing hydrophobic substances or a response through a different pathway that does not involve the $P R 1 A$ gene. For instance, proteins and other biomolecules can adsorb to nanomaterials forming a bio-corona [55-57], and its composition can change depending on the nanomaterial [58] and its functionalization [59]. Currently, studies of nanomaterial-corona formation in plants are scarce [60-62]. Species-specific bio-corona formation or other yet unidentified factors could account for the difference in stress response we observed, and further highlights the need for more studies using different nanomaterials and plant species to inform tailored nanomaterial functionalization.

Interestingly, when these stress responses were activated at lower levels by low concentrations of PEISWNTs, they were well tolerated by plants for several days. It remains to be studied if this temporal response 
could prime plants to better resist later biotic or abiotic stresses. Indeed, the observed PEI-SWNT response is similar to the one elicited by defense-priming agrichemicals used to confer long-lasting resistance to biotic [46] and abiotic stresses [47]. This opens the possibility of using low PEI-SWNT concentrations as stress-priming treatments. Development of new scalable and costefficient methods for SWNT synthesis would make this feasible in the future [63]. In fact, silica nanoparticles have recently been shown to enhance disease resistance through salicylic acid-mediated systemic acquired resistance [64]. Further work studying these and longer-term effects of PEI-SWNTs on plants are needed to explore this possibility.

The framework described in this work (transcriptomic profiling, marker identification and concentration/ time/functionalization-dependent response validation) could be adapted to study the plant responses to other agronomically-relevant nanomaterials with promising applications in different plant species. Once nanomaterial-plant interactions are better characterized, rational design of more biocompatible functionalized nanomaterials can be achieved for a broad range of plant biotechnology applications.

\section{Materials and methods}

\section{Nanomaterial preparation and characterization}

ssRNA-adsorbed SWNTs were prepared as described in [30]. Plasmid DNA adsorbed PEI-SWNTs were prepared as described in [29]. Free PEI (Sigma, cat. 408727) was dissolved in water and the same amount of plasmid DNA loaded onto PEI-SWNTs was added, obtaining a final PEI concentration of $627 \mathrm{ng} / \mu \mathrm{L}$. Other polymer-SWNTs were prepared as described in [51]: COOH-SWNTs were added to water in a $1 \mathrm{mg}: 1 \mathrm{~mL}$ ratio and dispersed via bath (10 $\mathrm{min}$ ) and probe-tip (30 min, 30-40 W) sonication. The resulting solution was centrifuged at $18,000 \mathrm{~g}$ for $1 \mathrm{~h}$. Afterwards, the supernatant was collected, and the concentration was measured via absorbance at $632 \mathrm{~nm}$ with an extinction coefficient of 0.036. COOHSWNT (1 mg) was dispersed in $100 \mathrm{mM}$ MES buffer and adjusted to a $\mathrm{pH}$ of 4.5-6. $\mathrm{N}$-(3-dimethylaminopropyl)$N^{\prime}$-ethylcarbodiimide hydrochloride (EDC) $(5 \mathrm{mg})$ and $\mathrm{N}$-hydroxysulfosuccinimide sodium salt (NHS) $(5 \mathrm{mg}$ ) were dissolved in $100 \mathrm{mM}$ MES solution $(2.5 \mathrm{~mL})$ and added dropwise to the SWNT mixture while stirring. The solution was bath sonicated for $15 \mathrm{~min}$ and then placed on an orbital shaker at $100 \mathrm{rpm}$ for $45-60 \mathrm{~min}$. The product was then washed three times with $0.1 \times$ PBS via spin filtration at $300 \mathrm{xg}$ for $\sim 8 \mathrm{~min}$ through a $100 \mathrm{~K} \mathrm{MWCO}$ filter. Each polymer $(20 \mathrm{mg})$ was dissolved in $0.1 \times$ PBS and adjusted to a pH between 7.4-7.6. The SWNT solution was added dropwise to the polymer solution while stirring. The $\mathrm{pH}$ was adjusted to a range of 7-8 and the solution was placed on an orbital shaker at $180 \mathrm{rpm}$ overnight. The resulting product was redispersed via probetip sonication (if significantly aggregated) and washed six times with water via spin filtration at $1000 \mathrm{~g}$ through a $100 \mathrm{~K}$ MWCO filter (1-20 min each, depending on the polymer). The product was resuspended via bath and probe-tip sonication, centrifuged, and the supernatant was collected. Elemental analysis $(\mathrm{C}, \mathrm{H}, \mathrm{N})$ was performed at the Microanalytical Laboratory at the University of California, Berkeley on a Perkin Elmer 2400 Series II combustion analyzer. Based on the Pregl-Dumas method, samples are combusted in a pure oxygen environment, with the resultant combustion gases measured in an automated fashion. The degree of functional groups was calculated by determining the total mass of $\mathrm{N}$ atoms in a branched PEI molecule (estimated as 580.5 PEI monomers per $25 \mathrm{kDa}$ molecular weight branched PEI polymer molecule) divided by the total $\mathrm{N}$ content of the product. This value was then divided by the remaining $\mathrm{C}$ content of the product.

\section{RNA-seq sample collection and preparation}

Wild-type Columbia-0 Arabidopsis thaliana and wildtype Nicotiana benthamiana plants were grown in the greenhouse and in a HiPoint 740FHLED growth chamber, respectively, under the following conditions: $24{ }^{\circ} \mathrm{C}$ high and $21^{\circ} \mathrm{C}$ low, $16 \mathrm{~h}$ light and $8 \mathrm{~h}$ dark, and $70 \%$ average humidity. Young leaves [65] of 6-week old wild-type Col-0 Arabidopsis plants in vegetative stage were selected to be fully infiltrated (approx. vol. $40 \mu \mathrm{L}$ ) with a $1 \mathrm{~mL}$ needleless syringe (BD, cat. no. 14-823-434) loaded with water, COOH-SWNTs $(50 \mathrm{mg} / \mathrm{L})$, SWNTs $(50 \mathrm{mg} / \mathrm{L})$, PEI-SWNTs $(50 \mathrm{mg} / \mathrm{L})$ or the panel of polymer-SWNTs $(50 \mathrm{mg} / \mathrm{L})$. The SWNT concentration was measured via absorbance at $632 \mathrm{~nm}$ with an extinction coefficient of 0.036 . The third and fourth leaves of 4-week-old Nicotiana plants were infiltrated in the same way. Two days after infiltration, five biological replicates containing four Arabidopsis leaves of each treatment from different plants and from non-treated plants were collected. For Nicotiana, a $1 \mathrm{~cm}$ by $1 \mathrm{~cm}$ infiltrated area was collected for each biological replicate. Samples were collected in a $2 \mathrm{~mL}$ Eppendorf tube with two $3.2 \mathrm{~mm}$ chrome steel beads (RPI, cat. no. 9840) and flash frozen in liquid $\mathrm{N}_{2}$ immediately. Frozen samples were ground in a Minibeadbeater (Biospec Products, cat. no. 3110Bx) tissue homogenizer for $5 \mathrm{~s}$ at $25 \mathrm{~Hz}$ frequency, twice.

RNA was extracted using RNeasy Plant Mini Kit (Qiagen cat. 74904) using RNase-Free DNase (Qiagen cat. 79254) following manufacturer instructions. Total RNA concentration was measured using the $\mathrm{Qubit}^{\mathrm{TM}} \mathrm{RNA}$ BR Assay Kit (Thermo Fisher). RNA quality was checked 
using a 2100 Bioanalyzer with RNA 6000 Nano Kit (Agilent). RNA integrity number (RIN) scores were confirmed to be $>8$. Libraries were prepared using Kapa Biosystems library preparation kit with mRNA selection with poly-A magnetic beads. Libraries were pooled and sequenced on an Illumina NovaSeq S4 flow cell in a NovaSeq 6000 Platform with 150 paired end reads. On average, 29.5 million reads per sample were obtained. Sequencing data discussed in this publication have been deposited in NCBI's Gene Expression Omnibus [66].

\section{Sequencing data analysis}

Raw reads were pre-processed using FastQC, and Trimmomatic was used to trim low quality reads [67]. HISAT2 was used to map the reads to the Arabidopsis genome (TAIR10) using default values [68]. FeatureCounts was used to assign reads to Arabidopsis transcripts (TAIR10) [69]. These steps were performed using the public server at usegalaxy.org [70]. Further analysis was performed in R [71]. edgeR was used to identify differentially expressed genes [72]. Briefly, genes with average RPKM values below one were removed from the analysis, then a model matrix was built to compare all the treatments against the non-infiltrated samples, and quasi-likelihood dispersion estimation and hypothesis testing were performed. Genes with a statistically significant $(F D R<0.05)$ two-fold expression change in at least one of the treatments with respect to the untreated samples were selected for further analysis. The ggupset $\mathrm{R}$ package was used for Fig. 1B. Gene Ontology Enrichment Analyses were performed using the clusterProfiler package [73] with GO annotations from org.At.tair.db version 3.11.4. GSEA analysis was performed using the fgsea package [74] with GO annotations or experimental databases Arapath [39] and PlantGSEA [40]. GO were aggregated by hierarchical clustering using relevance semantic similarity [75] and the most common ancestor term with the highest information content was selected as the representative GO term for each cluster. The 10 top experiments in Arapath and PlantGSEA databases with the highest positive NES in PEI-SWNT up-regulated genes and negative NES in PEI-SWNT down-regulated genes were selected for analysis. To identify gene clusters, row Z-scored $\log 2$ (fold change) values were clustered using Pearson's correlation as distance and a complete agglomeration method, and represented using ComplexHeatmap package [76].

\section{RNA expression analyses}

RNA was extracted from $100 \mathrm{mg}$ of ground leaves following the protocol described in [77] with certain modifications. We used TRIzol (Thermo cat.
15596026) instead of phenol and Phasemaker tubes were used to separate the aqueous phase (Thermo cat. A33248). $10 \mu \mathrm{g}$ of total RNA were treated with TURBO DNase I (Thermo cat. AM2238) and cDNA was synthetized using $1 \mu \mathrm{g}$ RNA using the High-Capacity cDNA Reverse Transcription Kit (Thermo cat. 4368814). PowerUP SYBR Green Master Mix (Thermo cat. A25741) was used for RT-qPCR using three technical replicates per reaction in a CFX96 Touch RealTime PCR Detection System (Biorad). Primers are described in Additional file 5: Table S5. SAND and EF1a genes were used as reference for Arabidopsis and Nicotiana, respectively [78]. For experiments in Nicotiana we identified the closest orthologs of Arabidopsis genes using their protein sequence as input in the solgenomics BLAST tool against the Nicotiana benthamiana genome [79]. We used the sequence of Niben101Scf00107g03008.1 (PR1A) and Niben101scf01817g00015.1 (NbAGP41).

\section{Supplementary Information}

The online version contains supplementary material available at https://doi. org/10.1186/s12951-021-01178-8.

Additional file 1: Table S1. Elemental analysis of PEI-SWNTs and source materials used in this study. Mass percentage of each element is reported. Degree of functionalization (DFG) refers to the fraction of carbons on the surface lattice that contain a branched PEI 25 k functional group, calculated as described in the methods section. This DFG represents a 12.54 PEI to SWNT ratio by mass (i.e., 50 ng of PEI-SWNTs contain 627 ng of PEI). Figure S1. Validation of RNA-seq data by RT-qPCR. (A) Normalized $\log 2$ (RPKM) values for selected genes from Clusters 1 and 2 (PEI-SWNT specific genes) and Clusters 4 and 6 (SWNT specific genes) from RNA-seq data. (B) mRNA levels of same genes as in (A) measured by RT-qPCR. The lower and upper hinges of the boxplot correspond to the first and third quartiles, the upper and lower whiskers correspond to the largest value no further than 1.5 times the inter-quartile range. Statistical significance was determined by a one-way ANOVA with post-hoc Tukey HSD test. Letters denote significant differences among means $(n=5$ in $A$ and $n=3$ in B). Figure S2. Infiltrated free PEl is more toxic than when conjugated to SWNTs. (A) Arabidopsis leaves infiltrated with water, free PEI (627 ng/ $\mu \mathrm{L})$ and PEI-SWNTs (50 ng/ $\mu \mathrm{L})$ 2-dpi. (B) mRNA levels of the selected marker genes measured by RT-qPCR in leaves of plants infiltrated as in (A). The lower and upper hinges of the boxplot correspond to the first and third quartiles, the upper and lower whiskers correspond to the largest value no further than 1.5 times the inter-quartile range. Statistical significance was determined by a one-way ANOVA with post-hoc Tukey HSD test. Letters denote significant differences among means $(n=3)$.

Additional file 2: Table S2. Genes that showed a statistically significant $(F D R<0.05)$ two-fold expression change with respect to the non-infiltrated samples in at least one treatment.

Additional file 3: Table S3. Gene Ontology over-representation analysis of differentially expressed genes in different treatments.

Additional file 4: Table S4. Gene Set Enrichment Analyses.

Additional file 5: Table S5. Primers used in RT-qPCR reactions.

\section{Acknowledgements}

We thank Frederic Bouche, parkjisun from Noun Project, and Natalie Goh for the graphics used in Fig. 1A. The GFP plasmid was obtained from the Sheen Lab (Harvard Medical School). We thank BASF for providing the L-PEI-800 and 
H-PEl polymers and Elena Kreimer of the Microanalytical Facility at UC Berkeley for running elemental analyses.

\section{Authors' contributions}

EG, GSD and MPL conceived the project, designed the experiments and wrote the manuscript. EG, GSD and CTJ performed the experiments. EG and DY performed data analysis. SE, KM and HK synthesised polymers. All authors have edited and commented on the manuscript and have given their approval of the final version. All authors read and approved the final manuscript.

\section{Funding}

We acknowledge support a Burroughs Wellcome Fund Career Award at the Scientific Interface (CASI) (to M.P.L.), a Dreyfus foundation award (to M.P.L.), a Beckman Foundation Young Investigator Award (to M.P.L.), an NIH MIRA award (to M.P.L.), an NSF CAREER award (to M.P.L), an NSF CBET award (to M.P.L.), an NSF CGEM award (to M.P.L.), a FFAR Young Investigator award (to M.P.L.), a CZI investigator award (to M.P.L), a Sloan Foundation Award (to M.P.L.), a USDA BBT EAGER award (to M.P.L), a USDA NIFA Award (to M.P.L), a Moore Foundation Award (to M.P.L.), and a DOE office of Science grant with award number DE-SC0020366 (to M.P.L.) and NSF GRFP (to C.T.J.). M.P.L. is a Chan Zuckerberg Biohub investigator, a Hellen Wills Neuroscience Institute Investigator, and an IGI Investigator.

\section{Availability of data and materials}

Sequencing dataset supporting the conclusions of this article is available in the Gene Expression Omnibus repository [66], under GEO Series accession number GSE172278.

\section{Declarations}

\section{Competing interests}

The authors declare that they have no competing interests.

\section{Author details}

'Department of Chemical and Biomolecular Engineering, University of California, Berkeley, CA, USA. ${ }^{2}$ BASF, Carl-Bosch-Strasse 38, 67056 Ludwigshafen am Rhein, Germany. Innovative Genomics Institute (IGI), Berkeley, CA, USA. ${ }^{4}$ California Institute for Quantitative Biosciences, QB3, University of California, Berkeley, CA, USA. ${ }^{5}$ Chan-Zuckerberg Biohub, San Francisco, CA, USA. ${ }^{6}$ Present Address: Department of Plant Biology and Genome Center, University of California, Davis, CA, USA.

Received: 12 August 2021 Accepted: 2 December 2021

Published online: 20 December 2021

\section{References}

1. Zhao L, Lu L, Wang A, Zhang H, Huang M, Wu H, et al. Nano-biotechnology in agriculture: use of nanomaterials to promote plant growth and stress tolerance. J Agric Food Chem Am Chem Soc. 2020;68:1935-47.

2. Sanzari I, Leone A, Ambrosone A. Nanotechnology in plant science: to make a long story short. Front Bioeng Biotechnol. 2019;7:120.

3. Singh H, Sharma A, Bhardwaj SK, Arya SK, Bhardwaj N, Khatri M. Recent advances in the applications of nano-agrochemicals for sustainable agricultural development. Environ Sci Process Impacts Roy Soc Chem. 2021;23:213-39.

4. Ahmar S, Mahmood T, Fiaz S, Mora-Poblete F, Shafique MS, Chattha MS, et al. Advantage of nanotechnology-based genome editing system and its application in crop improvement. Front Plant Sci. 2021;0:943.

5. Zuverza-Mena N, Martínez-Fernández D, Du W, Hernandez-Viezcas JA, Bonilla-Bird N, López-Moreno ML, et al. Exposure of engineered nanomaterials to plants: Insights into the physiological and biochemical responses - a review. Plant Physiol Biochem. 2017;1 10:236-64.

6. Miralles P, Church TL, Harris AT. Toxicity, uptake, and translocation of engineered nanomaterials in vascular plants. Environ Sci Technol Am Chemical Society. 2012;46:9224-39.
7. Remédios C, Rosário F, Bastos V. Environmental nanoparticles interactions with plants: morphological, physiological, and genotoxic aspects. J Bot Hindawi. 2012;2012:1-8.

8. Ma X, Geiser-Lee J, Deng Y, Kolmakov A. Interactions between engineered nanoparticles (ENPs) and plants: phytotoxicity, uptake and accumulation. Sci Total Environ Elsevier. 2010;408:3053-61.

9. Zheng $\mathrm{L}$, Hong F, Lu S, Liu C. Effect of nano-TiO ${ }_{2}$ on strength of naturally aged seeds and growth of spinach. Biol Trace Elem Res Springer. 2005;104:83-91.

10. Feizi H, Moghaddam PR, Shahtahmassebi N, Fotovat A. Impact of bulk and nanosized titanium dioxide $\left(\mathrm{TiO}_{2}\right)$ on wheat seed germination and seedling growth. Biol Trace Elem Res Springer. 2012;146:101-6.

11. Lin D, Xing B. Phytotoxicity of nanoparticles: inhibition of seed germination and root growth. Environ Pollut Elsevier. 2007;150:243-50.

12. Majumdar S, Ma C, Villani M, Zuverza-Mena N, Pagano L, Huang Y, et al. Surface coating determines the response of soybean plants to cadmium sulfide quantum dots. Nanolmpact. 2019;14:100151.

13. Begum P, Ikhtiari R, Fugetsu B. Graphene phytotoxicity in the seedling stage of cabbage, tomato, red spinach, and lettuce. Carbon NY Elsevier. 2011:49:3907-19.

14. Smirnova E, Gusev A, Zaytseva O, Sheina O, Tkachev A, Kuznetsova E, et al. Uptake and accumulation of multiwalled carbon nanotubes change the morphometric and biochemical characteristics of Onobrychis arenaria seedlings. Front Chem Sci Eng Springer. 2012;6:132-8.

15. Shen CX, Zhang QF, Li J, Bi FC, Yao N. Induction of programmed cell death in Arabidopsis and rice by single-wall carbon nanotubes. Am J Bot. 2010:97:1602-9.

16. Khodakovskaya MV, de Silva K, Nedosekin DA, Dervishi E, Biris AS, Shashkov EV, et al. Complex genetic, photothermal, and photoacoustic analysis of nanoparticle-plant interactions. Proc Natl Acad Sci. 2011;108:1028-33.

17. Canas JE, Long M, Nations S, Vadan R, Dai L, Luo M, et al. Effects of functionalized and nonfunctionalized single-walled carbon nanotubes on root elongation of select crop species. Environ Toxicol Chem. 2008:27:1922-31.

18. Ren L, Deng S, Chu Y, Zhang Y, Zhao H, Chen H, et al. Single-wall carbon nanotubes improve cell survival rate and reduce oxidative injury in cryopreservation of Agapanthus praecox embryogenic callus. Plant Methods. 2020;16:1-12. https://doi.org/10.1186/s13007-020-00674-6.

19. Singh S, Vishwakarma K, Singh S, Sharma S, Dubey NK, Singh VK, et al. Understanding the plant and nanoparticle interface at transcriptomic and proteomic level: a concentric overview. Plant Gene Elsevier. 2017;11:265-72.

20. Jha S, Pudake RN. Molecular mechanism of plant-nanoparticle interactions BT-plant nanotechnology: principles and practices. In: Kole C, Kumar DS, Khodakovskaya MV, editors. Cham: Springer International Publishing; 2016. p. 155-81.

21. Van Aken B. Gene expression changes in plants and microorganisms exposed to nanomaterials. Curr Opin Biotechnol Elsevier. 2015;33:206-19.

22. Landa P, Vankova R, Andrlova J, Hodek J, Marsik P, Storchova H, et al. Nanoparticle-specific changes in Arabidopsis thaliana gene expression after exposure to $\mathrm{ZnO}_{1} \mathrm{TiO}_{2}$, and fullerene soot. J Hazard Mater Elsevier. 2012:241:55-62.

23. García-Sánchez S, Bernales I, Cristobal S. Early response to nanoparticles in the Arabidopsis transcriptome compromises plant defence and root-hair development through salicylic acid signalling. BMC Genomics. 2015;16:341.

24. Wong MH, Giraldo JP, Kwak S-Y, Koman VB, Sinclair R, Lew TTS, et al. Nitroaromatic detection and infrared communication from wild-type plants using plant nanobionics. Nat Mater. 2017;16:264-72.

25. Giraldo JP, Wu H, Newkirk GM, Kruss S. Nanobiotechnology approaches for engineering smart plant sensors. Nat Nanotechnol Nature Publishing Group. 2019;14:541-53.

26. Lew TTS, Koman VB, Silmore KS, Seo JS, Gordiichuk P, Kwak S-YY, et al. Real-time detection of wound-induced $\mathrm{H}_{2} \mathrm{O}_{2}$ signalling waves in plants with optical nanosensors. Nat Plants. 2020;6:404-15.

27. Giraldo JP, Landry MP, Faltermeier SM, McNicholas TP, Iverson NM, Boghossian AA, et al. Plant nanobionics approach to augment photosynthesis and biochemical sensing. Nat Mater. 2014;13:400-8.

28. Wu H, Nißler R, Morris V, Herrmann N, Hu P, Jeon SJ, et al. Monitoring plant health with near-infrared fluorescent $\mathrm{H}_{2} \mathrm{O}_{2}$ nanosensors. Nano Lett Am 
Chem Soc. 2020;20:2432-42. https://doi.org/10.1021/acs.nanolett.9b051 59.

29. Demirer GS, Zhang H, Goh NS, González-Grandío E, Landry MP. Carbon nanotube-mediated DNA delivery without transgene integration in intact plants. Nat Protoc. 2019;14:2954-71.

30. Demirer GS, Zhang H, Goh NS, Pinals RL, Chang R, Landry MP. Carbon nanocarriers deliver siRNA to intact plant cells for efficient gene knockdown. Sci Adv. 2020;6:eaaz0495.

31. Kwak S-Y, Lew TTS, Sweeney CJ, Koman VB, Wong MH, Bohmert-Tatarev $\mathrm{K}$, et al. Chloroplast-selective gene delivery and expression in planta using chitosan-complexed single-walled carbon nanotube carriers. Nat Nanotechnol. 2019;14:447-55.

32. Demirer GS, Zhang H, Matos JL, Goh NS, Cunningham FJ, Sung Y, et al. High aspect ratio nanomaterials enable delivery of functional genetic material without DNA integration in mature plants. Nat Nanotechnol. 2019;14:456-64.

33. Schwartz SH, Hendrix B, Hoffer P, Sanders RA, Zheng W. Carbon dots for efficient small interfering RNA delivery and gene silencing in plants. Plant Physiol. 2020;184:647-57.

34. Wang B, Huang J, Zhang M, Wang $Y$, Wang $H, M a Y$, et al. Carbon dots enable efficient delivery of functional DNA in plants. ACS Appl Bio Mater. 2020;3:8857-64. https://doi.org/10.1021/acsabm.0c01170.

35. Chiu WL, Niwa Y, Zeng W, Hirano T, Kobayashi H, Sheen J. Engineered GFP as a vital reporter in plants. Curr Biol. 1996;6:325-30.

36. Pitsili E, Phukan UJ, Coll NS. Cell death in plant immunity. Cold Spring Harb Perspect Biol. 2020;12:a036483.

37. Lefevere H, Bauters L, Gheysen G. Salicylic acid biosynthesis in plants. Front Plant Sci. 2020;11:338. https://doi.org/10.3389/fpls.2020.00338/full.

38. Subramanian A, Tamayo P, Mootha VK, Mukherjee S, Ebert BL, Gillette MA, et al. Gene set enrichment analysis: a knowledge-based approach for interpreting genome-wide expression profiles. Proc Natl Acad Sci. 2005;102:15545-50.

39. Lai L, Liberzon A, Hennessey J, Jiang G, Qi J, Mesirov JP, et al. AraPath: a knowledgebase for pathway analysis in Arabidopsis. Bioinformatics. 2012;28:2291-2.

40. Yi X, Du Z, Su Z. PlantGSEA: a gene set enrichment analysis toolkit for plant community. Nucleic Acids Res. 2013;41:W98-103.

41. Pesaresi P, Hertle A, Pribil M, Kleine T, Wagner R, Strissel H, et al. Arabidopsis STN7 kinase provides a link between short- and long-term photosynthetic acclimation. Plant Cell. 2009;21:2402-23.

42. Jambunathan N, Penaganti A, Tang Y, Mahalingam R. Modulation of redox homeostasis under suboptimal conditions by Arabidopsis nudix hydrolase 7. BMC Plant Biol. 2010;10:173.

43. Singh P, Kuo YC, Mishra S, Tsai CH, Chien CC, Chen CW, et al. The lectin receptor Kinase-VI. 2 is required for priming and positively regulates Arabidopsis pattern-triggered immunity. Plant Cell. 2012;24:1256-70.

44. Li J, Brader G, Helenius E, Kariola T, Palva ET. Biotin deficiency causes spontaneous cell death and activation of defense signaling. Plant J. 2012;70:315-26

45. Delgado-Cerezo M, Sánchez-Rodríguez C, Escudero V, Miedes E, Fernández PV, Jordá L, et al. Arabidopsis heterotrimeric G-protein regulates cell wall defense and resistance to necrotrophic fungi. Mol Plant Oxford University Press. 2012;5:98-114.

46. Knoth C, Salus MS, Girke T, Eulgem T. The synthetic elicitor 3,5-dichloroanthranilic acid induces NPR1-dependent and npr1-independent mechanisms of disease resistance in Arabidopsis. Plant Physiol. 2009;150:333-47.

47. Skipsey M, Knight KM, Brazier-Hicks M, Dixon DP, Steel PG, Edwards R. Xenobiotic responsiveness of Arabidopsis thaliana to a chemical series derived from a herbicide safener. J Biol Chem. 2011;286:32268-76.

48. Tran LSP, Urao T, Qin F, Maruyama K, Kakimoto T, Shinozaki K, et al. Functional analysis of AHK1/ATHK1 and cytokinin receptor histidine kinases in response to abscisic acid, drought, and salt stress in Arabidopsis. Proc Natl Acad Sci USA. 2007;104:20623-8.

49. Li Y, Lee KK, Walsh S, Smith C, Hadingham S, Sorefan K, et al. Establishing glucose- and ABA-regulated transcription networks in Arabidopsis by microarray analysis and promoter classification using a relevance vector machine. Genome Res. 2006;16:414-27.

50. Duan K, Willig CJ, De Tar JR, Spollen WG, Zhang ZJ. Transcriptomic analysis of Arabidopsis seedlings in response to an Agrobacterium-mediated transformation process. Mol Plant-Microbe Interact. 2018;31:445-59.
51. Jackson CT, Wang JW, González-Grandío E, Goh NS, Mun J, Krishnan S, et al. Polymer-conjugated carbon nanotubes for biomolecule loading. bioRxiv. 2021;36:882. https://doi.org/10.1101/2021.07.22.453422v1.

52. Bally J, Nakasugi K, Jia F, Jung H, Ho SYW, Wong M, et al. The extremophile Nicotiana benthamiana has traded viral defence for early vigour. Nat Plants. 2015;1:1-6.

53. Wong MH, Misra RP, Giraldo JP, Kwak SY, Son Y, Landry MP, et al. Lipid exchange envelope penetration (LEEP) of nanoparticles for plant engineering: a universal localization mechanism. Nano Lett. 2016;16:1161-72. https://doi.org/10.1021/acs.nanolett.5b04467.

54. Lv J, Christie P, Zhang S. Uptake, translocation, and transformation of metal-based nanoparticles in plants: recent advances and methodological challenges. Environ Sci Nano. 2019;6:41-59.

55. Monopoli MP, Åberg C, Salvati A, Dawson KA. Biomolecular coronas provide the biological identity of nanosized materials. Nat Nanotechnol. 2012;7:779-86

56. Chetwynd AJ, Lynch I. The rise of the nanomaterial metabolite corona, and emergence of the complete corona. Environ Sci Nano. 2020;7:1041-60.

57. Voke E, Pinals RL, Goh NS, Landry MP. In planta nanosensors: understanding Biocorona formation for functional design. ACS Sens. 2021;6:2802.

58. Pinals RL, Yang D, Rosenberg DJ, Chaudhary T, Crothers AR, lavarone AT, et al. Quantitative protein corona composition and dynamics on carbon nanotubes in biological environments. Angew Chem Int Ed. 2020;59:23668-77. https://doi.org/10.1002/anie.202008175.

59. Sheibani S, Basu K, Farnudi A, Ashkarran A, Ichikawa M, Presley JF, et al. Nanoscale characterization of the biomolecular corona by cryo-electron microscopy, cryo-electron tomography, and image simulation. Nat Commun. 2021;12:1-9.

60. Prakash S, Deswal R. Analysis of temporally evolved nanoparticle-protein corona highlighted the potential ability of gold nanoparticles to stably interact with proteins and influence the major biochemical pathways in Brassica juncea. Plant Physiol Biochem. 2020;146:143-56.

61. Kurepa J, Smalle JA. Composition of the metabolomic bio-coronas isolated from Ocimum sanctum and Rubia tinctorum. BMC Res Notes. 2021;14.

62. Borgatta JR, Lochbaum CA, Elmer WH, White JC, Pedersen JA, Hamers RJ. Biomolecular corona formation on $\mathrm{CuO}$ nanoparticles in plant xylem fluid. Environ Sci Nano. 2021;8:1067-80.

63. Rao R, Pint $C L$, Islam AE, Weatherup RS, Hofmann S, Meshot ER, et al. Carbon nanotubes and related nanomaterials: critical advances and challenges for synthesis toward mainstream commercial applications. ACS Nano. 2018;12:11756-84. https://doi.org/10.1021/acsnano.8b06511.

64. El-Shetehy M, Moradi A, Maceroni M, Reinhardt D, Petri-Fink A, RothenRutishauser B, et al. Silica nanoparticles enhance disease resistance in Arabidopsis plants. Nat Nanotechnol 2021;16. https://doi.org/10.1038/ s41565-020-00812-0.

65. Panchuk II, Zentgraf U, Volkov RA. Expression of the Apx gene family during leaf senescence of Arabidopsis thaliana. Planta. 2005;222:926-32.

66. Edgar R, Domrachev M, Lash AE. Gene expression Omnibus: NCBI gene expression and hybridization array data repository. Nucleic Acids Res. 2002;30:207-10.

67. Bolger AM, Lohse M, Usadel B. Trimmomatic: a flexible trimmer for Illumina sequence data. Bioinformatics. 2014;30:2114-20.

68. Kim D, Langmead B, Salzberg SL. HISAT: a fast spliced aligner with low memory requirements. Nat Methods. 2015;12:357-60.

69. Liao Y, Smyth GK, Shi W. FeatureCounts: an efficient general purpose program for assigning sequence reads to genomic features. Bioinformatics. 2014;30:923-30.

70. Afgan E, Baker D, Batut B, Van Den Beek M, Bouvier D, Ech M, et al. The Galaxy platform for accessible, reproducible and collaborative biomedical analyses: 2018 update. Nucleic Acids Res. 2018;46:W537-44.

71. R Core Team. R: a language and environment for statistical computing [Internet]. Vienna, Austria; 2020. Available from: https://www.r-project. org/.

72. McCarthy DJ, Chen Y, Smyth GK. Differential expression analysis of multifactor RNA-Seq experiments with respect to biological variation. Nucleic Acids Res. 2012:40:4288-97.

73. Yu G, Wang LG, Han Y, He QY. ClusterProfiler: an R package for comparing biological themes among gene clusters. Omi A J Integr Biol OMICS. 2012:16:284-7. 
74. Sergushichev AA. An algorithm for fast preranked gene set enrichment analysis using cumulative statistic calculation. bioRxiv. 2016;31:608. https://doi.org/10.1101/060012v1.

75. Schlicker A, Domingues FS, Rahnenführer J, Lengauer T. A new measure for functional similarity of gene products based on gene ontology. BMC Bioinformatics. 2006;7:302. https://doi.org/10.1186/1471-2105-7-302.

76. Gu Z, Eils R, Schlesner M. Complex heatmaps reveal patterns and correlations in multidimensional genomic data. Bioinformatics. 2016;32:2847-9.

77. Toni LS, Garcia AM, Jeffrey DA, Jiang X, Stauffer BL, Miyamoto SD, et al. Optimization of phenol-chloroform RNA extraction. MethodsX. 2018;5:599-608

78. Czechowski T, Stitt M, Altmann T, Udvardi MK, Scheible W-R. Genomewide identification and testing of superior reference genes for transcript normalization in Arabidopsis. Plant Physiol. 2005;139:5-17.

79. Bombarely A, Rosli HG, Vrebalov J, Moffett P, Mueller LA, Martin GB. A draft genome sequence of Nicotiana benthamiana to enhance molecular plant-microbe biology research. Mol Plant-Microbe Interact. 2012;25:1523-30. https://doi.org/10.1094/MPMI-06-12-0148-TA.

\section{Publisher's Note}

Springer Nature remains neutral with regard to jurisdictional claims in published maps and institutional affiliations.

- fast, convenient online submission

- thorough peer review by experienced researchers in your field

- rapid publication on acceptance

- support for research data, including large and complex data types

- gold Open Access which fosters wider collaboration and increased citations

- maximum visibility for your research: over 100M website views per year

At BMC, research is always in progress.

Learn more biomedcentral.com/submissions 